\title{
GaMYB85, an R2R3 MYB gene, in transgenic Arabidopsis plays an important role in drought tolerance
}

\author{
Hamama Islam Butt, Zhaoen Yang, Qian Gong, Eryong Chen, Xioaqian Wang, Ge Zhao, Xiaoyang Ge, \\ Xueyan Zhang ${ }^{*}$ and Fuguang $\mathrm{Li}^{*}$
}

\begin{abstract}
Background: MYB transcription factors (TFs) are one of the largest families of TFs in higher plants and are involved in diverse biological, functional, and structural processes. Previously, very few functional validation studies on R2R3 MYB have been conducted in cotton in response to abiotic stresses. In the current study, GaMYB85, a cotton R2R3 MYB TF, was ectopically expressed in Arabidopsis thaliana (Col-0) and was functionally characterized by overexpression in transgenic plants.

Results: The in-silico analysis of GAMYB85 shows the presence of a SANT domain with a conserved R2R3 MYB imperfect repeat. The GaMYB85 protein has a 257-amino acid sequence, a molecular weight of $24.91 \mathrm{kD}$, and an isoelectric point of 5.58. Arabidopsis plants overexpressing GaMYB85 exhibited a higher seed germination rate in response to mannitol and salt stress, and higher drought avoidance efficiency than wild-type plants upon water deprivation. These plants had notably higher levels of free proline and chlorophyll with subsequent lower water loss rates and higher relative water content. Germination of GaMYB85 transgenics was more sensitive to abscisic acid (ABA) and extremely liable to ABA-induced inhibition of primary root elongation. Moreover, when subjected to treatment with different concentrations of ABA, transgenic plants with ectopically expressed GaMYB85 showed reduced stomatal density, with greater stomatal size and lower stomatal opening rates than those in wild-type plants. Ectopic expression of GaMYB85 led to enhanced transcript levels of stress-related marker genes such as RD22, ADH1, RD29A, P5CS, and ABI5.
\end{abstract}

Conclusions: Our results indicate previously unknown roles of GAMYB85, showing that it confers good drought, salt, and freezing tolerance, most probably via an ABA-induced pathway. These findings can potentially be exploited to develop improved abiotic stress tolerance in cotton plants.

Keywords: MYB transcription factor, Abiotic stress tolerance, Abscisic acid

\section{Background}

Environmental factors, particularly drought stress, severely limit the production and distribution of many important agronomic crops worldwide [1]. In plants, different types of transcription factors (TFs), such as bZIP, NAC, AP2, WRKY, and MYB, control plant biological processes by modulating the initiation rate of target genes with the combined activation of a DNA binding domain, a nuclear localization signal, a transcription

\footnotetext{
*Correspondence: Zhangxueyan_caas@126.com; aylifug@163.com State Key Laboratory of Cotton Biology, Institute of Cotton Research of

Chinese Academy of Agricultural Science (ICR, CAAS), Anyang 455000, China
}

activation domain, and oligomerization sites in response to biotic or abiotic stresses [2]. MYB TFs were first recognized as oncogenes in animals; however, it has subsequently been found that MYB genes occur more widely in plants than in animals and fungi $[3,4]$. Following the discovery of the first plant MYB gene in maize (Zea mays) [5], large numbers of MYB proteins, particularly R2R3 MYBs, have been extensively identified and characterized in different plant species, including Arabidopsis, apple, grape, maize, petunia, and snapdragon [6]. Furthermore, R2R3 MYBs are known to control abundant plant biological processes, such as hormone signal transduction, 
organ development, cell cycle progression, cellular morphogenesis, secondary metabolism, and stress responses [7, 8]. More recently, genome-wide studies of Gossypium raimondii have revealed 205 putative R2R3 MYB genes, which is a greater number than reported in any other dicot or monocot [9].

Structurally, MYB proteins have a highly conserved MYB or DBD (DNA-binding domain), located at the N terminus, which is well conserved across all eukaryotes, whereas the diverse $\mathrm{C}$ termini act as a trans-acting domain (TAD) that regulates a broad range of functions in MYB proteins [10, 11]. Moreover, each MYB repeat contains 52 amino acid residues with regularly spaced triplet tryptophan residues, which form a hydrophobic core structure. The MYB repeat structure is composed of three $\alpha$-helices. Two helices form the HTH (helix-turnhelix) structure and contribute to the binding of target genes to the promoter region, whereas the third helix participates in DNA recognition [12, 13]. On the basis of their DNA-binding domain sequential repeats, MYB proteins are grouped into four types; MYB1-R, R2R3MYB, R1R2R3-MYB (MYB3R), and 4R-MYB [14]. However, to improve drought tolerance in the relevant crops, mining of new MYB R2R3 TFs by functional genomics and comparative genomics studies is a promising strategy, as it is the largest family of MYB proteins of higher plants and well known to be involved in specific diverse biological, functional, and structural processes.

The phytohormone abscisic acid (ABA) has numerous functions, such as in seed germination inhibition and dormancy maintenance, stomatal regulation, flowering time, and adaptations to drought, cold, and salt stresses [15]. ABA is known to induce dehydration-responsive genes, and thus on encountering drought stress, elevated levels of ABA stimulate cis-acting and trans-acting factors, which in turn up-regulate the ABA-induced expression of MYB, NAC, WRKY, and bZIP TF genes [16-19], thereby contributing to the relief of stress conditions [20]. Many ABA-inducible genes contain a cis-element (ABRE; ACGTGG/TC), whereas dehydration and low temperature stress-inducible genes contain a different ciselement (DRE; TACCGACAT). Both these elements play important roles in stress management via ABA-dependent and -independent signal transduction cascades [15, 21]. Moreover, $M Y C / M Y B$ recognition sequences are a prerequisite for transcript regulation of $R D 22$ and $A D H 1$, which is induced by high ABA levels in Arabidopsis under drought stress [22]. In addition, different R2R3 MYB genes (AtMYB44, AtMYB15, AtMYB60, AtMYB96, AtMYB61, and GbMYB5) have been shown to be involved in stomatal regulation via $\mathrm{ABA}$ in response to dehydration [23-25]. R2R3 MYB TFs are implicated in diverse plant responses to abiotic stress conditions. For example, the AtMYB102 protein is reported to be an important component that integrates wounding, osmotic stress, and ABA transduction pathways in transgenic Arabidopsis [26]. Similarly, overexpression studies on R2R3 MdSIMB1 [27], OsMYB2 [28], GmMYBJ1 [29], GmMYBJ2 [30], GbMYB5 [25], GmMYB76 [31] and SbMYB8 [32], have shown improved drought, salt, and cold tolerance in transgenic plants.

Cotton is an important textile fiber and oil seed crop [33]; however, the repercussions of climate change, particularly drought stress, are severely limiting its production globally [34]. Our laboratory previously released Gossypium arboreum sequencing data [35] and RNA-seq studies have revealed hormone crosstalk, whereby MYB TFs are implicated in modifying plant responses toward drought and $\mathrm{NaCl}$ stresses in different tissues [36]. Thus, in view of the current scenario, we ectopically expressed a novel G. arboreum R2R3 MYB gene, designated GaMYB85, in Arabidopsis to study its role under drought, salt, and freezing stress conditions. Collectively, our results suggest that the GaMYB85 gene confers good drought tolerance in overexpressing transgenic Arabidopsis plants, which can potentially be employed in future cotton crop improvement.

\section{Results}

\section{GaMYB85 characterization and phylogenetic analysis}

Previously, our mRNA-seq studies of G. arboreum showed multiple hormone crosstalk and tissue-selective signaling; moreover, MYB transcription factors are implicated in modifying cotton plant responses toward PEG and $\mathrm{NaCl}$ stresses in leaf, stem, and root [36]. Therefore, characterization of a novel gene, GaMYB85, was performed in transgenic Arabidopsis plants subjected to drought and salt stresses. The full-length CDS of GaMYB85 is 771 bp long, and codes for a protein containing 257 amino acids with an expected molecular weight of $24.91 \mathrm{kD}$ and a theoretical isoelectric point of 5.58 (http://web.expasy.org). Performing SMART analysis (available online at http://smart.embl-heidelberg.de/), the deduced 257-residue polypeptide was determined to contain a SANT domain between amino acids 38 and 86 . The secondary structure of GaMYB85 includes 19.53\% alpha helix, 19.53\% extending chain, and $60.94 \%$ random coil sequences. GaMYB85 alignment results between cDNA and genomic sequence retrieved from the cotton genome database revealed that the gene contains no introns (Additional file 1), and is located on chromosome 13 with a cotton ID number of cotton_A_21601. The deduced GaMYB85 protein shares a high amino acid sequence homology with AtMYB85 (At4g22680). Overexpression of this protein in Arabidopsis resulted in the ectopic deposition of lignin in epidermal and cortical cells of the stem [37], and it was thus 
designated as GaMYB85 in further studies. Multiple sequence alignment revealed high similarity between GaMYB85 and retrieved R2R3 protein homologs of various dicots and monocots, including Gossypium hirsutum (98\%), Nicotiana tabacum (82\%), Arabidopsis thaliana (79\%), Theobroma cacao (78\%), Zea mays (84\%), Hordeum vulgare (80\%), Oryza sativa (70\%), Triticum aestivum (66\%), and Vitis vinifera (61\%), which are annotated as predicted, putative, and hypothetical, and thus their functions are still unknown. However, they show the presence of conserved R2 and R3 domains in the MYB gene (http://www.ebi.ac.uk/Tools/msa/muscle/) (Fig. 1a). Moreover, in the phylogenetic tree we constructed, we also included some R2R3 MYB genes with known functions, which confer enhanced tolerance to multiple abiotic stresses. GaMYB85 shared high similarity and clustered together with its homologs from G. hirsutum, $V$. vinifera, and $T$. cacao, which indicates that they might have originated from the same common ancestor. Therefore, these results suggest that GaMYB85 is a novel gene that confers enhanced drought tolerance (Fig. 1b). LcMYB1, which has a single conservered SANT domain, belongs to a MYB-related protein, and was used as an outgroup in the tree.

\section{Overexpression of 35S:GaMYB85 in plants confers ABA} hypersensitivity for seed germination and root elongation In order to gain an understanding of the possible roles of GaMYB85 during germination and post-germination stages in response to abiotic stresses, this gene was ectopically expressed in Arabidopsis thaliana (Col-0) plants using the floral dip method. $\mathrm{T}_{2}$ seeds were selected on BASTA agar plates, and subsequently the surviving to dead plant ratio was determined (Additional files 2 and 3). Ten segregating lines with a correct segregation ratio of $3: 1$ were selected and transcript patterns were subsequently monitored by qRT-PCR (Fig. 2b and Additional file 5). Three lines with high gene transcript levels were selected and screened on selective media until we obtained homozygous lines. The $\mathrm{T}_{3}$ transgenic lines L3, L4, and L7 were selected for further analysis.

To examine the ABA sensitivity of transgenic plants containing ectopically expressed 35S:GaMYB85, the seeds of L3, L4, and L7 lines and WT plants were grown directly on medium containing different concentrations of $\operatorname{ABA}(0,0.3,0.5,1,2$, and $5 \mu \mathrm{M})$, and the germination rates of these were compared. In a primary root length elongation assay, the 35S:GaMYB85 lines were more susceptible to ABA (Fig. 3a and b) than was the WT, which indicates that ABA might be involved in the root development process, and also strengthens speculation that 35S:GaMYB85 is regulated in an ABA-dependent manner. The presence of exogenous ABA had a more pronounced effect on the germination rates of 35S:GaMYB85 lines (L3, L4, and L7) than on that of the WT (Fig. 3c). Only $25 \%$ of the seeds of the 35S:GaMYB85 lines (L3, L4, and L7) were able to germinate on $2 \mu \mathrm{M}$ ABA MS, as against 50\% germination for the WT. Furthermore, a detailed time course experiment was conducted on $1 \mu \mathrm{M}$ ABA (Fig. 3d), in which the seeds of 35S:GaMYB85 lines showed more delayed germination rates than the WT, starting from the 4th to 8th day after the onset of germination.

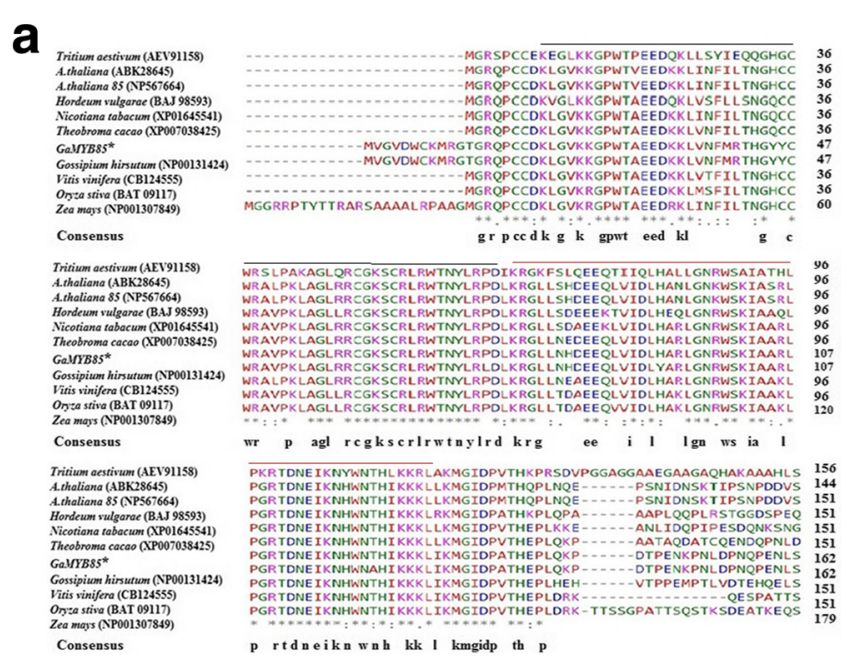

b

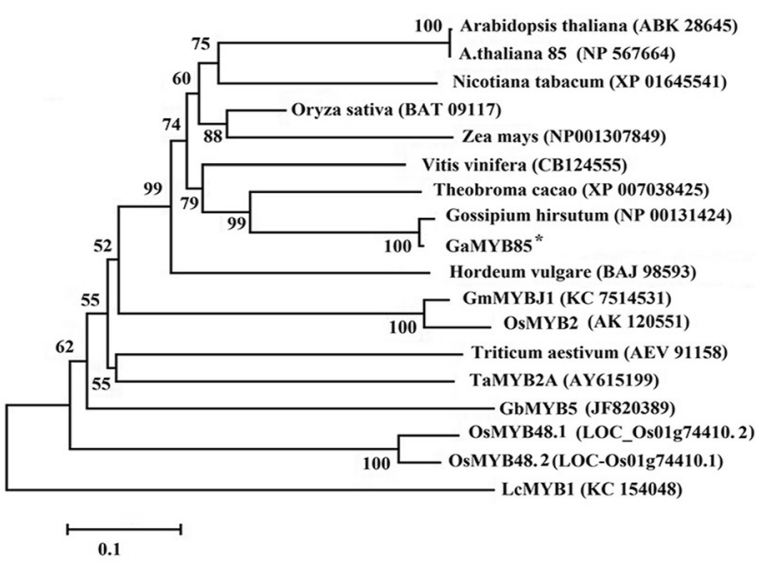

Fig. 1 The Phylogenetic analysis and predicted structure of R2R3 MYB GaMYB85. a Homologous sequences retrieved by Blast p were aligned with GaMYB85 showing R2 and R3 repeats represented by black and red lines respectively. b The NJ tree analysis of GaMYB85 proteins with homologous and known R2R3 MYB monocots and dicots sequences, along with scale bar that shows the calculated distance by multiple sequence alignment (MSA). The MSA of the respective sequences were provided in Additional file 1 

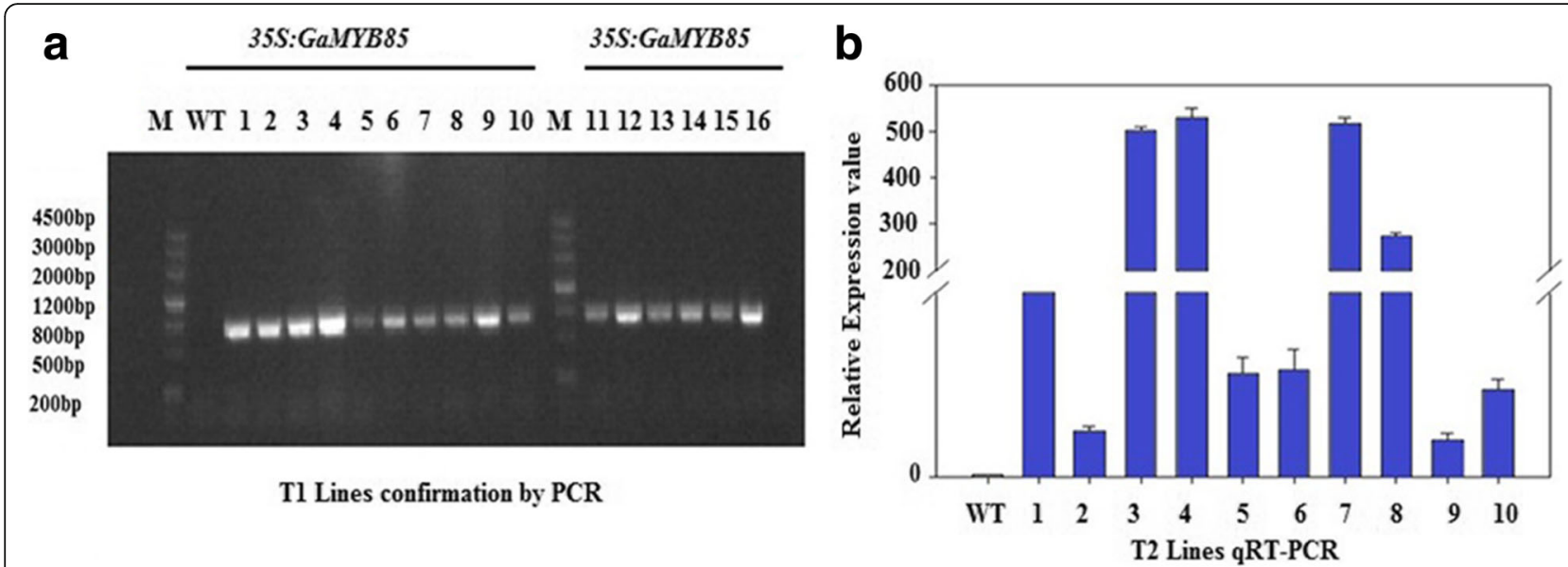

Fig. 2 Gel and qRT-PCR analysis of GaMYB85 transgenic plants a The confirmation of GaMYB85 gene CDS (771 bp) integration in To generated overexpressed Arabidopsis plants. The DNA of WT (Col-0) was used as negative control (lane 1) and 35S:GaMYB85 DNA was used in (lanes 1-10, 11-16). M; DNA marker III, 1 kb. b Relative expression of GaMYB85 gene in $T_{2}$ transgenic lines by qRT-PCR having segregating ratio of 3:1 on the selective medium, three cDNA preparations were used and error bars represented with SD value. AtUBQ10 gene (Accession no: AT4G05320) was used as an internal standard in qRT-PCR

\section{Overexpression of 35S:GaMYB85 in plants confers enhanced salt and osmotic tolerance}

For further clarification of the effects of $\mathrm{NaCl}$ stress on 35S:GaMYB85 plants, seed germination and postgermination growth were monitored. The results revealed $100 \%$ germination rates for control and test seeds that were grown in control MS medium. In contrast, the germination rates of 35S:GaMYB85 lines (L3, L4, and L7) were significantly higher than those of the WT on $\mathrm{NaCl}$ medium $(50,100,125$, and $150 \mathrm{mM}$ ) in a dose-dependent manner. Moreover, these plants had higher fresh weights than WT plants, which turned yellow and produced a proportion of unviable seeds (Fig. 4a, b, and c). Primary root growth is an important indicator of plant tolerance to various stress responses, and 35S:GaMYB85 transgenic seedlings showed longer roots and had greener broader rosettes than did the control when raised on $100 \mathrm{mM} \mathrm{NaCl}$ medium (Fig. 4d and e). Furthermore, compared with the WT, the germination rate and fresh weight of 35S:GaMYB85-expressing plants were significantly higher, and growth performance was improved under $300 \mathrm{mM}$ mannitol stress for $10 \mathrm{~d}$ (Fig. 5a, b, and c). Moreover, a root length assay on mannitol also revealed a significant difference in transgenic line root length growth on 200 and $300 \mathrm{mM}$ mannitol medium from that in the WT (Fig. $5 \mathrm{~d}$ and e). These significantly higher germination rates on simulated salt and mannitol stressed medium indicate that ectopic expression of GaMYB85 in Arabidopsis confers enhanced salt and osmotic tolerance during pre- and post-seed germination stages.

\section{Plants with GaMYB85 overexpression show enhanced tolerance under drought and freezing stress}

MYB TFs have been implicated in diverse plant responses to abiotic stress conditions [26]. For a drought assay, 7-d-old transgenic and WT seedlings were transplanted to well-hydrated soil, and then 2 weeks later, grown L3, L4, and L7 plants were subjected to drought stress. The WT plants showed lower recovery rates of $35 \%$ along with severe drought symptoms, such as leaf rolling, shrinkage, and delayed growth, when compared with the $66.66 \%, 77.8 \%$, and $70 \%$ recovery rates of GaMYB85 transgenic plants (L3, L4, and L7, respectively) following re-watering for $3 \mathrm{~d}$ (Fig. $6 \mathrm{a}$ and b). In accordance with these results, the water loss rate, which is an important indicator of drought stress evaluation, was significantly lower for transgenic lines when excised leaf weights were monitored over a 0 - to 7 -h time interval (Fig. 6c). The relative water content (RWC) in detached leaves of L3, L4, and L7 was approximately 71\%, 81.9\%, and $79.9 \%$, respectively, whereas the RWC for WT decreased by up to $55 \%$ (Fig. 6d). Subsequently, proline and chlorophyll content were evaluated in non-stressed and drought-stressed samples. The free proline content in GaMYB85-expressing plants was higher under both normal and drought stress conditions. The proline content in overexpressing L3, L4, and L7 plants was significantly higher $(19.8,27.5$, and $20.7 \mu \mathrm{g} / \mathrm{g}$, respectively) than that in the WT (almost $9 \mu \mathrm{g} / \mathrm{g}$ ) under drought stress (Fig. 6e and f). In addition, the total chlorophyll content under the non-stressed condition was nearly the same in WT and overexpressing L3, L4, and L7 plants. However, under drought stress, the total chlorophyll 


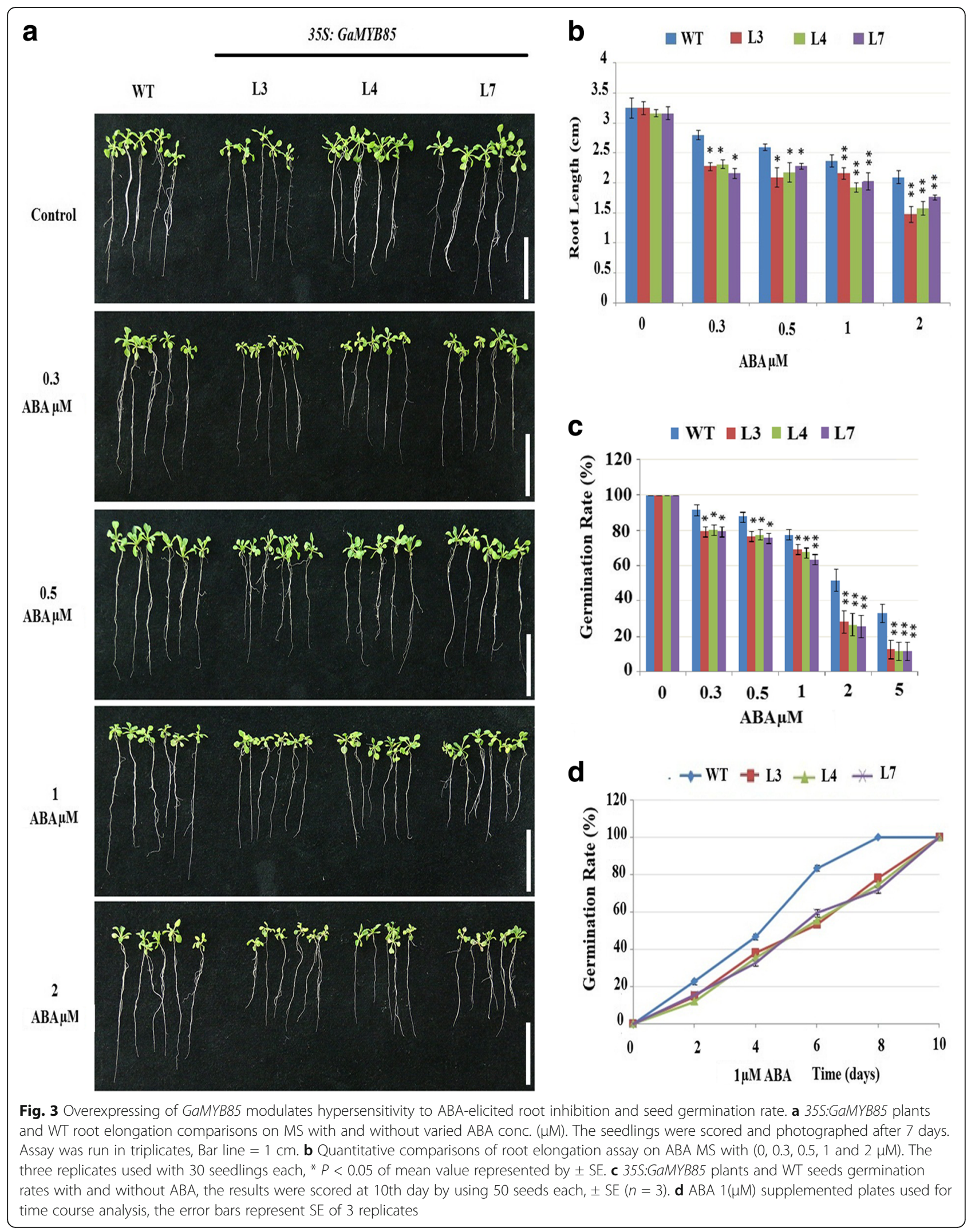




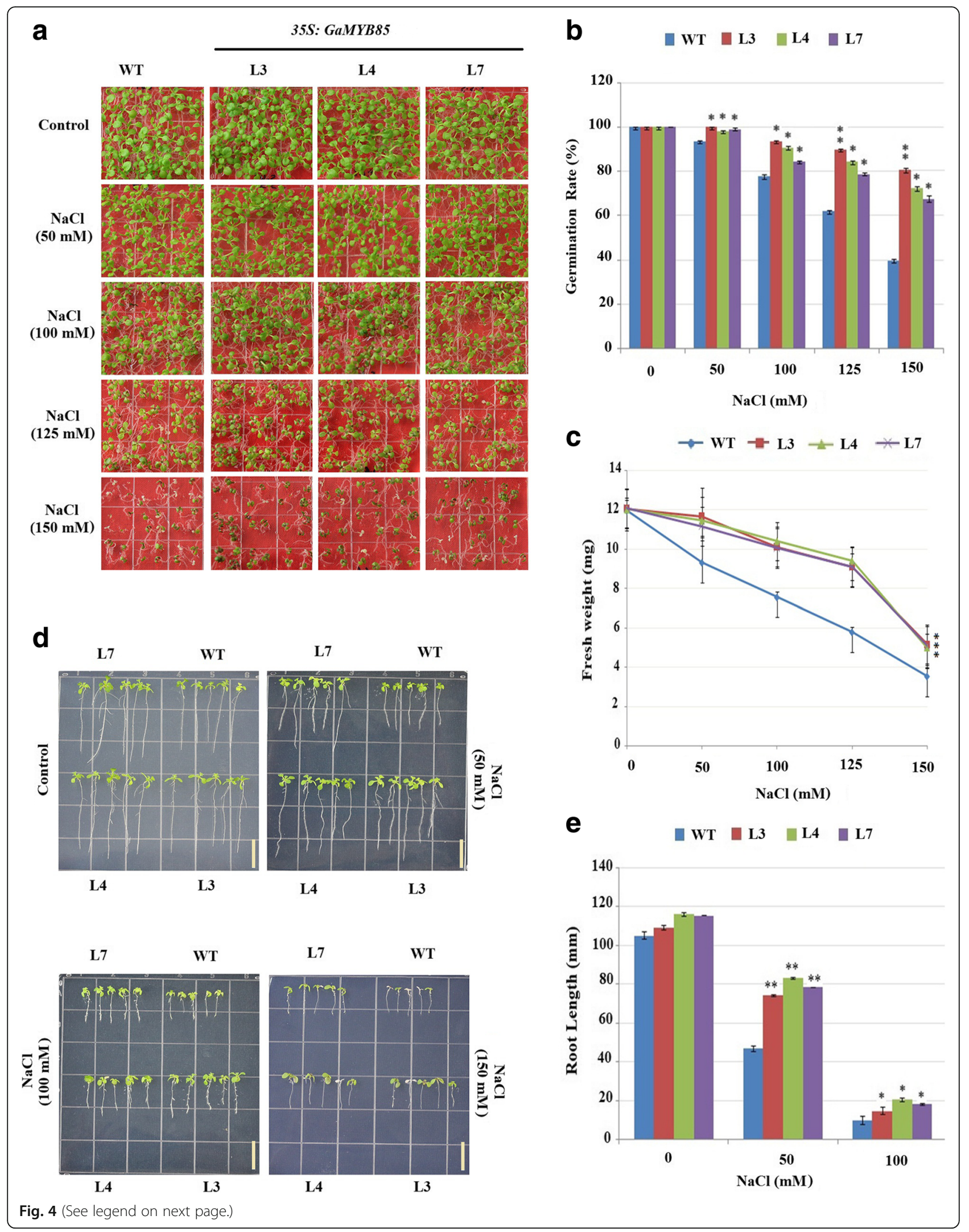


(See figure on previous page.)

Fig. 4 Overexpressing of GaMYB85 enhances germination and root length in response to NaCl stress. a 35S:GaMYB85 plants and WT seed germination rates on MS and MS supplemented with 0-150 mM salt were photographed at 10th day of seed germination. $\mathbf{b}$ The seed germination rates plot scored at 10th day for both transgenic and WT on salt medium, 50 seeds each were used in three biological replicates $(n=3),{ }^{*} P<0.05$ calculated by t-test with means values \pm SE. c 35S:GaMYB85 and WT seedlings fresh weights, grown on MS media with 0-150 mM NaCl, scored at 10th day of germination. 10 seedlings each used with three technical repeats and error bars with mean values \pm SE. $\mathbf{d}$ Root elongation comparisons of 35S:GaMYB85 and WT on 0-150 mM NaCl MS for 6 days. The data scored from three independent growth assays. Line bar: $1 \mathrm{~cm}$. e Quantitative comparison of root elongation of 35S:GaMYB85 and WT seedlings on MS supplemented with 0-150 mM NaCl. 30 seedlings each, $\left({ }^{*} P<0.05\right)$ calculated by t-test and mean value \pm SE $(n=3)$

content of GaMYB85 plants was higher than that in WT plants. When 3-week-old Arabidopsis lines (L3, L4, and L7) ectopically expressing GaMYB85 and WT plants were exposed to a $-10{ }^{\circ} \mathrm{C}$ treatment for $3 \mathrm{~h}$, and subsequently revived in a $22 \pm 1{ }^{\circ} \mathrm{C}$ growth room, the plants ectopically expressing GaMYB85 showed improved recovery rates of $55.55 \%, 75 \%$, and $69.44 \%$, respectively. The adverse effect of freezing stress was more pronounced in the WT plants, which showed only $34 \%$ survival after 1 week of growth in the $22 \pm 1{ }^{\circ} \mathrm{C}$ growth room (Fig. $7 \mathrm{a}$ and b). Overall, these results indicate that ectopically expressed GaMYB85 in Arabidopsis plays an important role under drought and freezing stresses.

\section{Reduced stomatal density, increased stomatal response, and increased stomatal size in GaMYB85 plants}

ABA production under abiotic stresses is directed to increase the sensitivity of stomatal closure, and thus to gain insight into this process, we examined the effects of ABA treatment on the stomatal opening of excised leaves of GaMYB85 plants (Fig. 8a). When different concentrations of ABA ( $5 \mu \mathrm{M}$ and $10 \mu \mathrm{M})$ were added to a stomata opening solution, stomatal opening was reduced, as ABA induces stomatal closure. Excised leaves of GaMYB85 lines (L3, L4, and L7) treated with $5 \mu \mathrm{M}$ ABA showed reduced stomatal opening rates of $40 \%-$ $56 \%$, which was further reduced to approximately $13.3 \%-23.3 \%$ under $10 \mu \mathrm{M}$ ABA treatments. In contrast, WT plants had markedly higher stomatal opening rates of $73 \%$ and $50 \%$ under 5 and $10 \mu \mathrm{M} \mathrm{ABA}$ treatments, respectively (Fig. 8b). Moreover, WT stomatal density was also notably higher, at more than 127 per $\mathrm{mm}^{2}$, than with 96, 111, and 112 per $\mathrm{mm}^{2}$ for L3, L4, and L7, respectively (Fig. 8c and d). However, stomatal size (length to width dimensions) in L3, L4, and L7 was distinctly higher at $21-25 \mu \mathrm{m}$ by $7-8.6 \mu \mathrm{m}$ when compared with the $19 \mu \mathrm{m}$ by $6.05 \mu \mathrm{m}$ for the WT, as shown in Fig. 8e. Hence, GaMYB85 reduced stomatal density and reduced stomatal opening, resulting in rapid ABA-induced stomata closure, which subsequently minimized water loss rates and led to improved drought tolerance.
Transcript analysis of abiotic stress-responsive marker genes

As Arabidopsis thaliana plants with constitutive overexpression of 35S:GaMYB85 have ABA-dependent enhanced drought tolerance, in addition to increased stomatal closure upon ABA treatment, it would be of interest to gain a further understanding of how GaMYB85 affects and responds to ABA stressresponsive and signaling-related genes. To this end, eight abiotic stress-responsive genes (RD22, RD29A, RD29B, P5CS, COR15A, CBF, ADH, and Rab18) and two ABA signaling genes ( $A B I 5$ and $A B I 3)$ were selected and studied. The expression levels of five stress-responsive genes (RD29B, COR15A, CBF, Rab18, and ABI3) were nearly the same in both transgenic and WT plants in ABA-treated samples (data not shown here). However, the expression levels of five genes (RD22, RD29A, P5CS, $A D H 1$, and $A B I 5)$ were significantly and clearly higher in L3, L4, and L7 than in the WT when treated with $100 \mu \mathrm{M}$ ABA for $6 \mathrm{~h}$ (Fig. 9a-e). Thus, in response to ABA treatment, the transcript levels of ABA-induced stress marker genes may positively contribute to the improved drought stress tolerance of GaMYB85 plants.

\section{Discussion}

Drought stress is a worldwide dilemma that has severely affected the annual production of cotton crops. Transcription factors are well known to participate in the maintenance of plant homeostasis in response to various biotic and abiotic factors. MYB TFs, particularly R2R3 MYBs, have been widely studied in different plant species, but to date few of these genes have been functionally validated for cotton. On the basis of diploid cotton A sequencing data [35], a new candidate cloned R2R3 MYB gene, designated GaMYB85, was selected and ectopically expressed in Arabidopsis thaliana, and three overexpressing lines (L3, L4, and L7) were successfully generated and functionally validated for drought stress. The amino acid sequence of GaMYB85 was predicted to contain a conservered SANT-DBD and clusters phylogenetically with R2R3 MYB proteins from other monocots and dicots, indicating that the R2R3 MYB proteins that group together may retain an identical function based on high sequence similarity. Some R2R3 


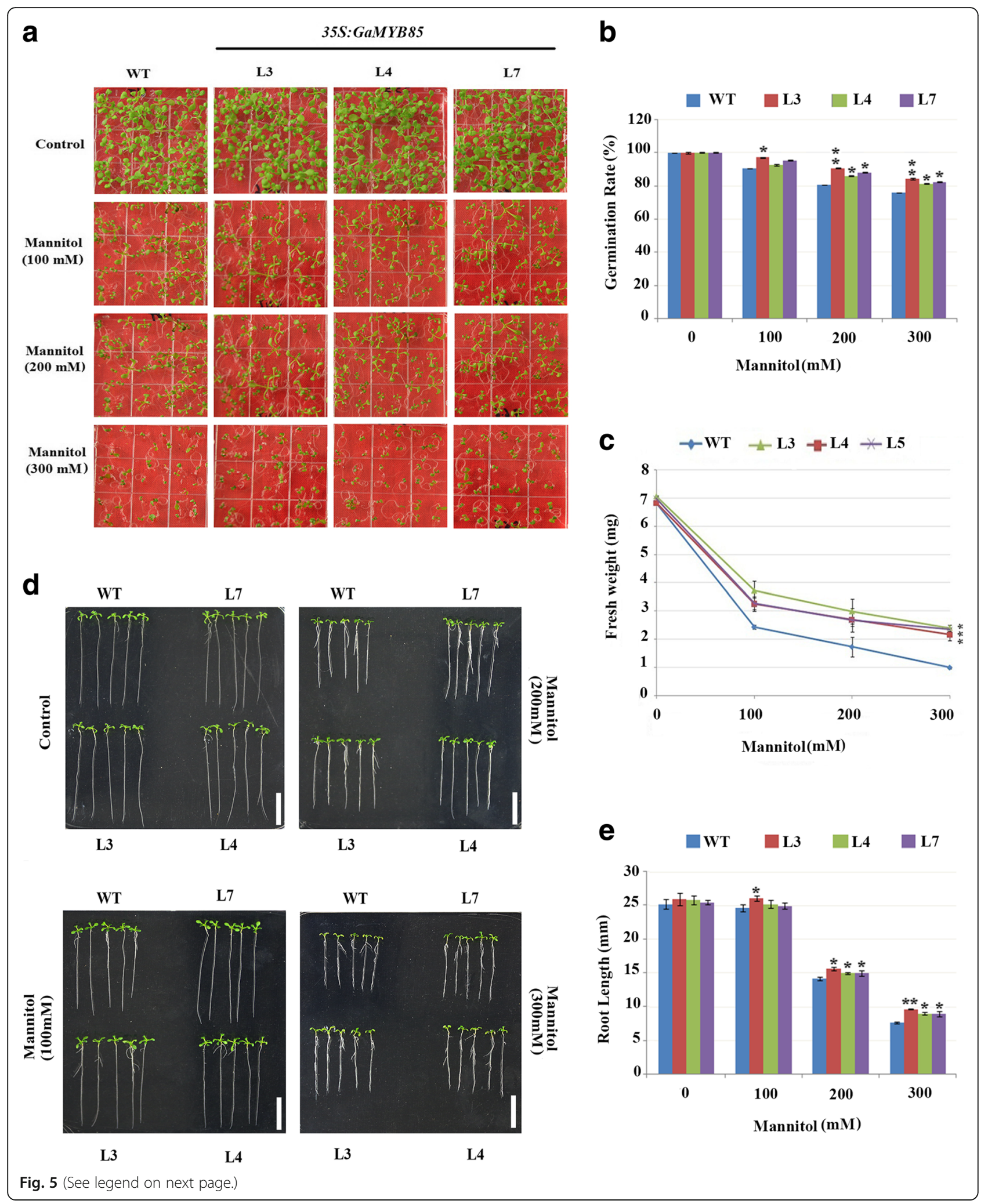


(See figure on previous page.)

Fig. 5 Plants overexpressing GaMYB85 perform well in response to mannitol stress a 35S:GaMYB85 and WT seed germination performance on MS supplemented with 0, 100, 200, and $300 \mathrm{mM}$ mannitol. Germination rates were scored on the 10th day. $\mathbf{b}$ A plot of the germination rates scored on the 10th day for 35S:GaMYB85 and WT seeds germinated on the different mannitol media. Data are the means \pm SE for three replicates of 50 seeds each $(* P<0.05)$. c Fresh weights of seedlings grown on 0-300 mM mannitol MS medium scored on the 10th day. Each treatment with 10 seedlings was performed in triplicate. Data are the means \pm SE $\left({ }^{*} P<0.05\right)$. d Comparison of root elongation of 5-day-old seedlings of 35S:GaMYB85 and WT plants transferred to 0, 100, 200, and 300 mM mannitol MS for 6 days. Values represent the data from three independent growth assays. Scale bar: $1 \mathrm{~cm}$. e Quantitative comparison of root elongation of 35S:GaMYB85 and WT seedlings on MS supplemented with 0-300 mM mannitol (30 seedlings each). Data are the means \pm SE $(n=3) . P<0.05$ determine by the t-test

MYBs with a known role in drought response were also included in a tree analysis (Additional file 2). These share a high similarity with GaMYB85 but cluster in different groups, which indicates that they might have a different number of SANT domains. Accordingly, these findings suggest that GaMYB85 is a novel R2R3 MYB gene with a SANT-DBD domain.

Environmental stimuli like drought and salt stresses specifically initiate $\mathrm{ABA}$ production, which induces stomatal closure, contributing to strong and healthy roots and plants with efficient stomatal regulation and water-retaining abilities [38, 39]. Furthermore, droughttolerant plants have higher endogenous proline content, reduced water loss rates, and improved relative water content, which enhance the response potential of transgenic plants against stress. Thus, to evaluate and dissect the possible molecular mechanisms and physiological roles underlying plant tolerance, we generated transgenic Arabidopsis that ectopically expressed GaMYB85. The important finding is that 35S:GaMYB85 lines have normal growth with respect to the WT, which is in contrast to previous studies in which transgenic overexpressing plants showed stunted growth and poor seed germination rates [40, 41].

In plants, turgor regulation plays an important role in the management of low water potential for normal seed germination rates under abiotic stress conditions. Thus, the observation that our 35S:GaMYB85 plants had higher germination rates when subjected to $300 \mathrm{mM}$ mannitol and $150 \mathrm{mM} \mathrm{NaCl}$ treatments indicated that they have a general osmotic stress tolerance. The adverse effects of salt on plant growth can either result in osmotic stress or specific ion toxicity. The osmotic stress phase is attributable to dehydration or the presence of salt in the external solution, but specific ion toxicity is a consequence of salt accumulation in the transpiring leaves. Moreover, seeds germination rates are dependent on water movement into the seeds, whereas exposure to salinity causes leaf cells to lose water, which is attributed to reduced turgor pressure or decreased cell wall expansion [42-44]. These results are in accordance with the functions of AtMYB102, AtMYB41, and GmMYBJ2, which have been demonstrated to confer improved drought tolerance in response to ABA-dependent osmotic and
$\mathrm{NaCl}$ stresses [3, 26, 30]. As elevated levels of salt can interfere with the normal molecular functioning of plants [45], 35S:GaMYB85 transgenic plants might have coped with this situation via ion homeostasis mechanisms, i.e., $\mathrm{Na}^{+}$ion extrusion, $\mathrm{Na}^{+}$ion compartmentalization, and $\mathrm{Na}^{+}$ion reabsorption [46-48]. The roots of plants are in direct contact with the soil and more sensitive to $\mathrm{Na}^{+}$ion stress, and thus provide important clues regarding normal plant growth [49]. Thus, 35S:GaMYB85 plants show a dose-dependent increase in root length growth upon salt treatment when compared with WT plants, but as transgenic plants show good fresh weight it implies that ionic stress was manifested. Furthermore, the primary root growth of seedlings was significantly decreased in WT plants growing on 200 and $300 \mathrm{mM}$ mannitol MS, which clearly demonstrates the high osmotic tolerance exhibited by the 35S:GaMYB85 plants [50, 51]. As ABA hypersensitivity and insensitivity of seeds can occur during germination and post-germination stages under water deficit stress, our 35S:GaMYB85 plants were confirmed to have enhanced sensitivity to ABA both at the germinating and post-germinating stages, along with hypersensitivity to ABA inhibition of root elongation [52, 53] as shown in Fig. $3 \mathrm{~b}$ and c. It is considered that $\mathrm{ABA}$ dependence might up-regulate the growth of roots and might be the major route by which 35S:GaMYB85 mediates its role in drought, salt, and cold stress signaling pathways [54, 55].

Constitutive overexpression of 35S:GaMYB85 in plants also resulted in better drought tolerance than in WT plants, which is further supported by the phenotypic and physiological changes that occur in these plants, such as decreased water loss rates and higher RWC. These results are consistent with the functional studies on GmMYBJ2 and TaMYB19, which have been reported to be associated with good drought tolerance ability $[30,56]$. An evaluation of water loss rates and RWC is imperative to elucidate drought avoidance mechanisms and indicates a balance between water availability and transpiration rates through the stomatal apertures of transgenic plants [57, 58]. 35S:GaMYB85 plants showed slower and lower rates of water losses with higher RWC capacity than WT plants (Fig. 6c and d), which 


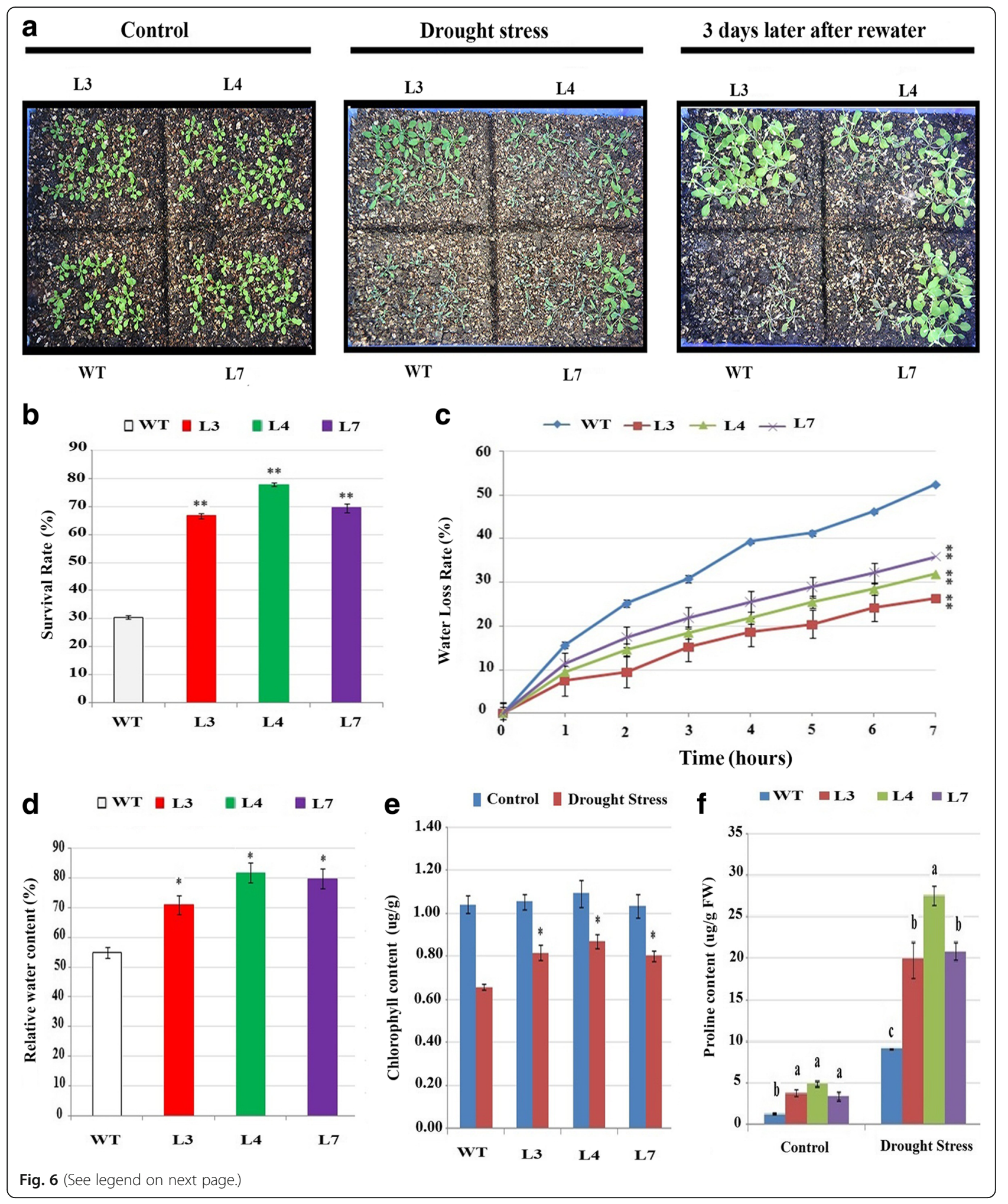


(See figure on previous page.)

Fig. 6 The characterization of 35S:GaMYB85 under drought stress. a The phenotypes of 35S:GaMYB85 and WT at the initial and late stages of dehydration and 3 days after re-watering $\mathbf{b}$ Survival percentages are the mean values \pm SE of three separate assays $(n=18)$. ${ }^{*} P<0.05$ and ** $P<0.01$ determined by the $t$ test. $\mathbf{c}$ Water loss rates of detached leaves of 3-week-old 35S:GaMYB85 and WT plants, expressed as percentages of initial fresh weight \pm SE $(n=10)$ and $\left({ }^{*} P<0.05\right)$. d Relative water content in detached leaves of 4-week-old 355 :GaMYB85 and WT plants. Data are the means \pm SD $(n=10)$. Significant differences $\left({ }^{*} P<0.05\right.$, ${ }^{* *} P<0.01$ and $\left.{ }^{* * *} P<0.001\right)$ were determined by Student's t-test. e Proline content of 35S:GaMYB85 and WT plants under normal conditions and after 14 days of water deprivation. For concentration determinations, absorbances were measured spectrophotometrically and Duncan's multiple range test was used for comparing means. Data are biological replicate means \pm SE $(n=3)$

is corroborated by recent reports on the R2R3 MYBs GmMYBJ1 and OsMYB48-1 [29, 59]. The total chlorophyll content of plants is linked to the physiological and transpiration efficiency of the photosynthetic machinery [60], whereas the osmoprotective molecule proline is critical for maintaining cell membrane stability, and also contributes to balancing osmotic pressure and retaining the membrane integrity of plants subjected to abiotic stresses [61]. In 35S:GaMYB85 plants, the chlorophyll and proline contents were significantly higher than those in WT plants (Fig. 6e and f), which suggests that endogenous proline levels contribute to the alleviation of water deficit stress and protect the photosynthetic apparatus from unfavorable toxic byproducts that have lethal effects on plant cells, and thereby confer drought tolerance. Interestingly, the proline levels in 35S:GaMYB85 transgenic plants are higher, even under normal condition, which suggests that this R2R3 MYB protein might specifically protect plants and confer drought tolerance via the integrated role of proline as an important osmoprotectant. Consequently, water deficit treatment indicates that drought avoidance is not only controlled by osmotic signaling but also depends on ABA-induced regulation of stomatal movement. To confirm this supposition, we examined various stomatal parameters to determine the possible roles of $35 \mathrm{~S}: \mathrm{GaMYB85}$ plants in attaining good drought tolerance. In our study, 35S:GaMYB85 plants were revealed to have greater stomatal size, lower stomatal densities, and lower rates of stomatal

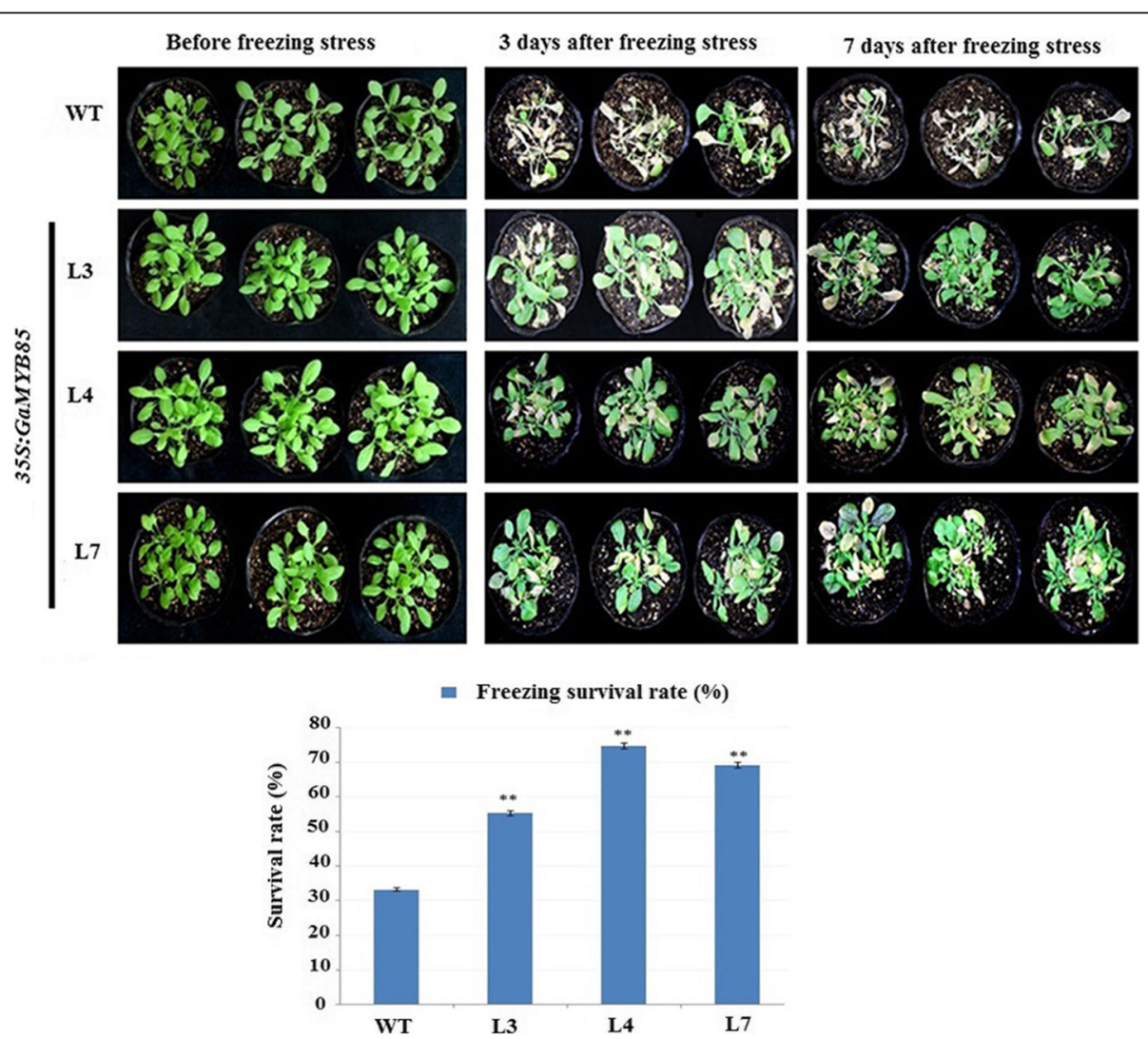

Fig. 7 Freezing stress responses of 35S:GaMYB85 and WT plants. 35S:GaMYB85 and WT plants at $-10{ }^{\circ} \mathrm{C}$ treatment, the photographs were taken after 7 days of plants revival. The survival rate percentage evaluated from three separate assays, mean values \pm SD $(n=18)$ and significant difference ${ }^{*} P<0.05$, calculated by t-test 

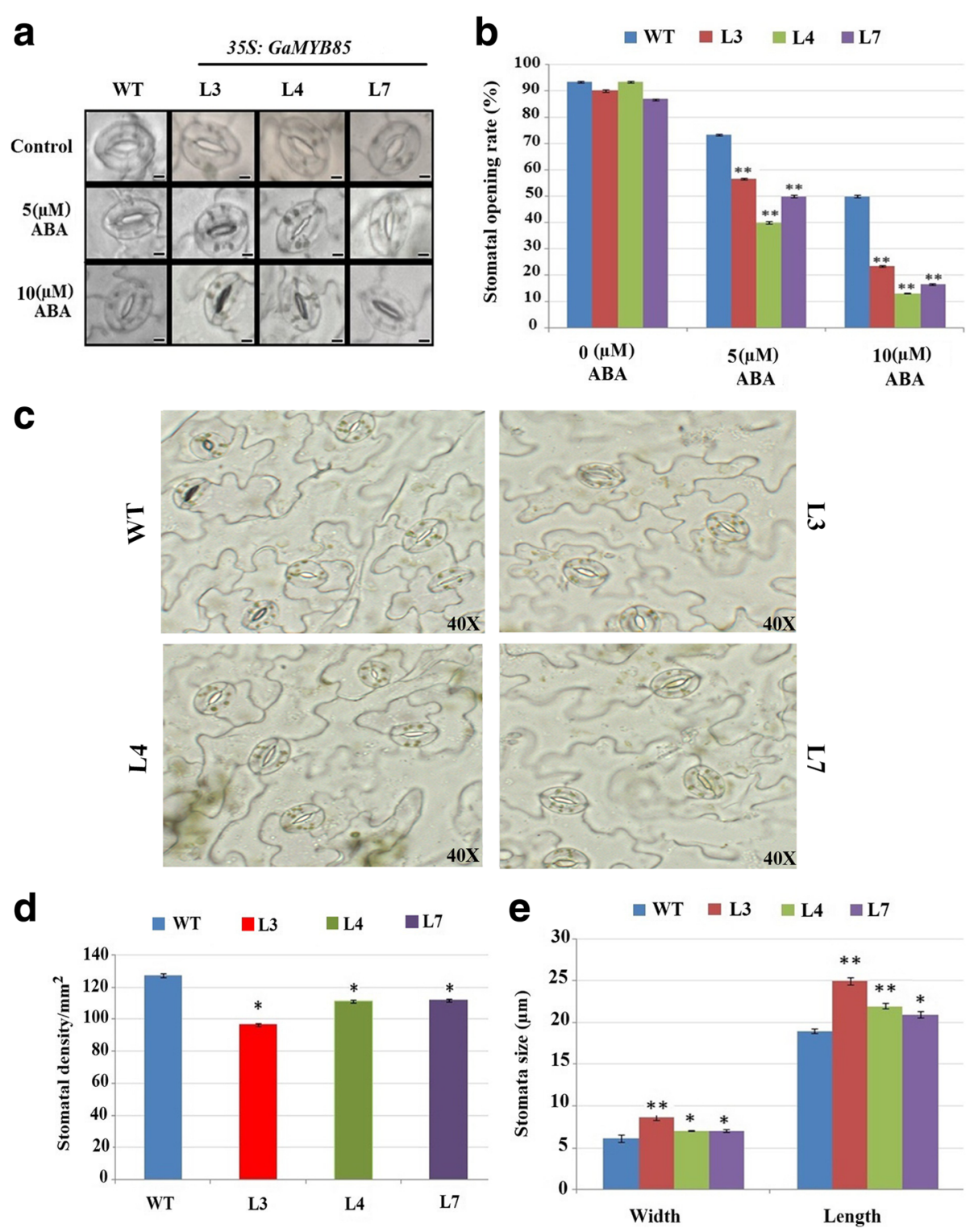

Fig. 8 ABA induces positive stomatal modulation in 35S:GaMYB85-overexpressing lines. a The stomatal pores of 35S:GaMYB85 and WT were photographed following treatment with 0,5 , and $10 \mu \mathrm{M}$ ABA. Five views from three replicate plants were observed at $\times 40$ magnification b Quantitative comparisons of the stomatal pores of 35S:GaMYB85 and WT plants following treatment with 0, 5, and $10 \mu \mathrm{M}$ ABA. The data shown are the mean values of three replicates \pm SD $(n=10)$. Scale bars: approximately $1 \mu \mathrm{m}$ c Leaf stomatal density of 35S:GaMYB85 and WT plants photographed under an OLYMPUS B×51 microscope at $\times 40$ magnification. $\mathbf{d}$ Quantitative comparisons of 35S:GaMYB85 and WT stomatal density e Width and length of guard cells measured using ImageJ software. Measurements were taken from the leaves of three plants (10 stomata from five microscopic views). Data are the means $\pm \mathrm{SD}$. ${ }^{*} P<0.05 ;{ }^{*} P<0.01$

opening than those of WT plants in response to exogenous ABA (Fig. 8b-e). These results corroborate the findings of previous studies on 35S:HDG11-transformed tobacco, which has reduced stomatal densities but increased stomatal size [62], and are in contrast to GbMYB5 transgenic tobacco plants, which have reduced stomatal size but the same stomatal density [25]. However, both these transgenic plants have high drought tolerance as a result of superior water retention abilities, lower transpiration rates, and reduced stomatal apertures due to elevated ABA production. Interestingly, 35S:GaMYB85 plants have reduced stomatal density but enlarged stomatal size, which can result in enhanced photosynthetic ability of plants by some unknown mechanism. This warrants further studies to gain insights into the possible function of the ABA transduction pathway in GaMYB85mediated roles in reduced stomatal apertures, which 


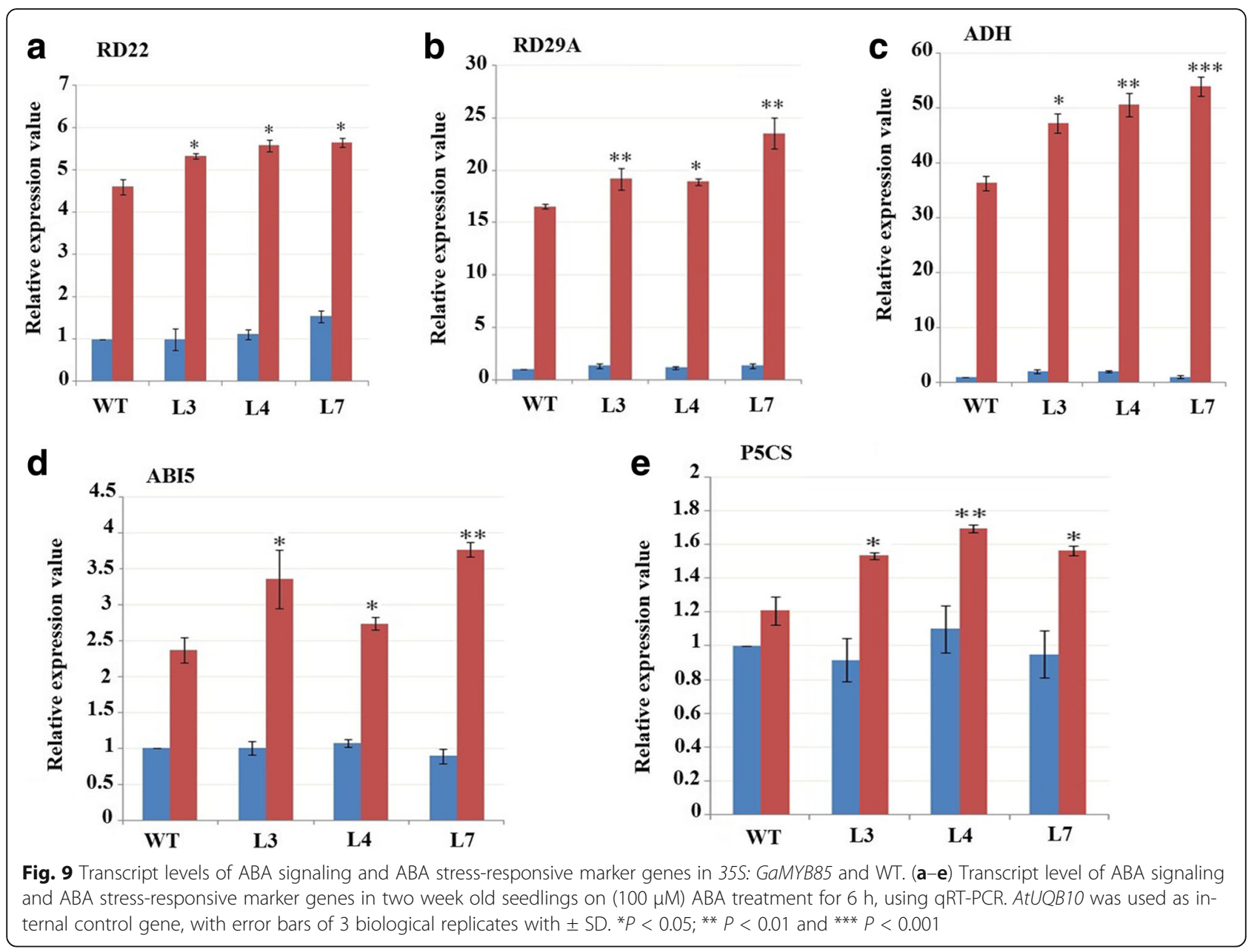

helps to maintain a balance between the rates of transpiration and photosynthetic capabilities of plant during drought stress responses.

Moreover, several overexpression studies have demonstrated the use of ABA-related marker genes involved in stress-related phenotypes in Arabidopsis [31, 56, 63]. Similarly, 35S:GaMYB85 overexpression led to the up regulation of RD22, RD29A, ADH1, AB15, and P5CS. The $A B 15$ gene encodes a bZIP TF, and is an ABA-responsive gene known to play a prominent role during the seed germinating period during drought stress [64, 65]. Moreover, D-pyrroline-5-carboxylase synthetase (P5CS) plays a key role in the initiation step for proline synthesis during dehydration or osmotic stress, and it has been revealed that up-regulation of the P5CS gene in 35S:GaMYB85 plants corroborated well with the findings of studies on OsMYB48-1, AtLOS5, and TaNAC47 $[52,53,59]$. The $R D 29 A$ gene codes for a hydrophilic protein and is known for the presence of DRE or related promoter motif regions. It is activated by the combined action of DRE and ABRE cis motif elements, which enables it to work both in ABA-dependent and
ABA-independent manners [66]. ABA-responsive expression of $R D 22$ is mainly due to co-expression activation of AtMYB2/AtMYC2. This is in contrast to $A D H 1$, which only requires activated AtMYB2 to act in a protective protein [67]. The above findings for GaMYB85 imply that it functions in an ABA-dependent manner, and plays an important role in drought stress tolerance, which has important implications for breeding droughttolerant cotton varieties.

\section{Conclusions}

To summarize, ectopic expression of GaMYB85 in Arabidopsis led to enhanced drought avoidance, elevated survival rates, higher accumulation of the compatible osmolyte proline, good germination rates under osmotic and salt stress, reduced water loss rates with improved RWC, increased ABA sensitivity at the germination and post-germination stages, a reduction in the number of ABA-induced stomatal apertures, and up-regulated transcription of ABA-mediated stress-responsive marker genes. In the light of the results of this study, we speculate that 35S: GaMYB85 could confer good drought, salt, 
and freezing tolerance in cotton crops. Our observations on the activity of the R2R3 MYB transcription factor GaMYB85 in transgenic Arabidopsis plants greatly enhances our perception about its possible function in response to environmental cues, and it can be considered as a novel candidate gene for future developments in cotton breeding.

\section{Methods}

\section{Transgenic plant construction and screening}

The presence of the $C a M V-35 S$ promoter driven pCAMBIA3300-GaMYB85 construct in A. tumefaciens strain GV3101 was confirmed using a GaMYB85 sense and antisense primer pair (Additional file 3), and was ectopically expressed in $A$. thaliana (Col-0) using the floral dip method with minor modifications [68]. The infiltration media used for transformation comprised $2.215 \mathrm{~g} / \mathrm{L} \mathrm{MS}$ containing $50 \mathrm{~g} / \mathrm{L}$ of sucrose, $0.5 \mathrm{~g} / \mathrm{L}$ of MES, $(330 \mu \mathrm{L} / \mathrm{L})$ of Silwet-77 and $0.01 \mathrm{mg} / \mathrm{L}$ of 6-BA at $\mathrm{pH} 5.7$. The infiltrated Arabidopsis was grown under the following conditions: $16 \mathrm{~h}$ light $/ 8 \mathrm{~h}$ dark, $60 \% \mathrm{RH}$, and $22^{\circ} \mathrm{C}$. Transgenic $\mathrm{T}_{0}$ seedlings were screened using $1 \mathrm{mg} / \mathrm{L}$ BASTA, which was sprayed twice on 7-d-old seedlings grown in soil pots (Additional file 4). The surviving seedlings were set to obtain $\mathrm{T}_{1}$ seeds, which were then confirmed for T-DNA integration in transgenic plants using a PCR Mighty Amp Genotyping Kit (Takara, China) as shown in (Fig. 2a), using the sense $35 \mathrm{~S}$ primer and the antisense gene primer. Wild-type (WT) plants were used as a control. Ten $\mathrm{T}_{2}$ lines with the correct segregation ratio (3:1) were selected and confirmed by qRT-PCR (Fig. 2b). Three $\mathrm{T}_{3}$ homozygous lines were selected and used for functional validation investigations (Additional file 5).

\section{Germination and root elongation assays}

To evaluate germination in response to simulated osmotic, salt, and ABA stresses, seeds from 35S:GaMYB85 transgenic lines (L3, L4, and L7) and WT were sterilized, stratified, and sown in triplicate on half-strength MS supplemented with different mannitol concentrations $(0,100,200$, and $300 \mathrm{mM})$, exogenous $\mathrm{ABA}(0,0.3,0.5$, $1,2$, and $5 \mu \mathrm{M})$ and $\mathrm{NaCl}(0,50,100,125$, and $150 \mathrm{mM}$ ). The plants were scored based on non-green phenotype or dead cotyledons on the 10th day postgermination [69]. Furthermore, for seedling root length elongation assay on mannitol-, $\mathrm{NaCl}-$, and ABAsupplemented MS, the methods described by [63] were followed. Three independent experiments were conducted and significant differences were determined using Student's t-test.

\section{Drought and freezing tolerance assay}

$\mathrm{T}_{3}$ homozygous transgenic line (L3, L4, and L7) and WT seeds were sterilized with $10 \%$ bleach for $10 \mathrm{~min}$, rinsed with water, and stratified at $4{ }^{\circ} \mathrm{C}$ for 3 days before the seeds were transferred to MS. One-week-old seedlings were transferred from MS to pots containing a wellwatered vermiculite and humus mix, and grown for 2 weeks. Thereafter, water was withheld for 2 weeks to simulate drought stress treatment. Subsequently, pots were re-watered and plant revival rates were scored after $3 \mathrm{~d}$. Plants showing green healthy leaves after water replenishment were scored as surviving. The ratios of surviving to dead plants were calculated and the experiment was repeated three times [62]. For the freezing tolerance experiment, 3-week-old overexpressing transgenic lines and control WT plants were subjected to a temperature of $-10^{\circ} \mathrm{C}$ for $3 \mathrm{~h}$. Subsequently, survival rates were calculated as previously described by [52]. All experiments were repeated three times using seeds of WT plants and the three transgenic lines independently.

\section{Measurements of transpirational WLR and RWC}

The water loss rate was determined as described by [70]. Detached leaves from 4-week-old test and control plants were immediately weighed to determine fresh weights (FW). Thereafter, at various time intervals, weights were recorded while samples were retained on a bench at $22{ }^{\circ} \mathrm{C}$ RT with a humidity level of $45 \% \pm 5 \%$. Fresh weights were calculated relative to plant initial weights. The relative water content of leaves was calculated using the method described by [71]. RWC percentage $=(F W-D W) /$ $(\mathrm{TW}-\mathrm{DW}) \times 100$. After determining fresh weights, the leaves were submerged in water for $4 \mathrm{~h}$ and turgid weights (TW) were recorded. Dry weights (DW) of leaves were recorded by drying samples at $80{ }^{\circ} \mathrm{C}$ for approximately $72 \mathrm{~h}$.

\section{Proline and chlorophyll contents}

Endogenous proline content in drought-stressed transgenic and WT plants was measured using a colorimetric PRO Kit (Jiancheng Bioengineering Institute, Nanjing, China). Three biological repeats were used, and proline absorbances at a wavelength of $520 \mathrm{~nm}$ were measured for determination of proline concentration.

Chlorophyll content was calculated using the formula described by [72] as follows: ((O.D $665 \mathrm{~nm} \times 13.95-$ O.D $649 \mathrm{~nm} \times 6.88)+($ O.D $649 \mathrm{~nm} \times 24.96-$ O.D $665 \mathrm{~nm} \times 7.32)) /($ sample weight). The sample extraction was performed using $0.1 \mathrm{~g}$ of rosette leaves in $1.5 \mathrm{~mL}$ $95 \%$ ethanol at RT in a dark room. The absorbances of extracted chlorophyll were measured at $649 \mathrm{~nm}$ and $665 \mathrm{~nm}$. Test and control samples were measured three times and the results were averaged. The means were compared using Duncan's multiple range test. 


\section{Stomatal measurements and determination of opening rate in response to abscisic acid treatment}

To investigate if stomatal pore closure is sensitive to ABA, we examined the effect of ectopic expression of GaMYB85 on stomatal opening rate of leaves under a microscope. The stomatal pores were initially opened by placing detached leaves from 3-week-old plants in a stomata opening solution $(10 \mathrm{mM} \mathrm{CaCl} 2,50 \mathrm{mM} \mathrm{KCl}$, and 5 mM MES, pH 6.15) [73] for $2 \mathrm{~h}$ in an illuminated growth chamber at $95 \%$ RH. Stomatal apertures were determined after $2.5 \mathrm{~h}$. Two concentrations of ABA ( 5 and $10 \mu \mathrm{M})$ were applied, whereas control experiments were performed without using ABA. Samples of young leaf epidermis of transgenic and WT plants were peeled and observed under an OLYMPUS Bx51 microscope for stomata density evaluation and measurement of guard cell width to length ratio. IMAGEJ 1.51d software [74] was used to measure the size of guard cells.

\section{Expression analysis of marker genes by qRT-PCR}

For transcript analysis of stress-responsive marker genes, 2-week-old transgenic and WT seedlings treated with $100 \mu \mathrm{M}$ ABA were used. RNA extraction was performed using an RNA-prep Pure Plant kit (Tiangen, China), followed by first-strand cDNA synthesis using PrimeScript RT Master Mix (Takara, Clontech, China). Quantitative RT-PCR was carried out using a 7900HT detection system (Applied Biosystems), using SYBR Premix $\operatorname{ExTaq}^{\text {Tw }}$ (Takara, Clontech, China) according to manufacturer's protocol. AtUBQ10 (Accession no: AT4G05320) was used as a control gene. Three biological replicates were run using independent cDNA preparations and three technical replicates, and relative transcripts were computed using the $2^{-\Delta \Delta \mathrm{Ct}}$ method based on CT values [75].

\section{Sequence and phylogenetic analysis}

GaMYB85 was retrieved from the cotton genome project database (http: //cgp.genomics.org.cn/page/species/blast.jsp.) and designated GaMYB85 (cotton_A_21601). Motif analysis was performed using SMART (http://smart.embl-heidelberg.de/), whereas intron-exon analysis was carried out using the GENE Structure Display Server available online (http://gsds.cbi.pku.edu.cn). GaMYB85 protein physio-chemical properties, such as MW and pI, were evaluated using the ExPASy proteomic portal (http:// www.expasy.org/proteomics). Monocot and dicot R2R3 MYB homologs were retrieved using the Blastp tool (https://www.ncbi.nlm.nih.gov/) and known R2R3 MYB were used in the construction of a cladogram based on the neighbor-joining method using MEGA 6.0. The multiple sequence alignment of GaMYB85 R2R3 homologs was performed using the EMBL-EBI Muscle online tool (http://www.ebi.ac.uk/Tools/msa/muscle/).

\section{Statistical analysis of data}

Statistical analysis was performed on data derived from three independent replicate experiments, using analysis of variance and Student's t-test. Duncan's multiple range test was applied to determine variation among treatment means of test and control lines.

\section{Additional files}

Additional file 1: Bioinformatics sequence analysis of GaMYB85 protein. (DOC $660 \mathrm{~kb}$ )

Additional file 2: Alignment of GaMYB85 with the deduced homologous amino acid sequences of R2R3 MYB retrieved from Blastp NCBI and known R2R3 MYB. (DOCX $469 \mathrm{~kb})$

Additional file 3: The primers sequences used for GAMYB85 study. (DOCX $13 \mathrm{~kb}$ )

Additional file 4: 35S:GaMYB85 over-expressed positive transgenic plants screening in BASTA screening at $T_{0}$ and $T_{3}$ stages. (DOCX $1186 \mathrm{~kb}$ )

Additional file 5: Survival percentage of 35S:GaMYB85 transgenic plants in 6\% BASTA selection medium. (DOCX $11 \mathrm{~kb}$ )

\section{Abbreviations}

ABA: Abscisic acid; DBD: DNA binding domain;" DW: Dry weight; FW: Fresh weight; GaMYB85: Gene in Gossipium arboreum; kD: kilo Dalton; mM: millimolar; MW: Molecular weight; OD: Optical density; pl: Isoelectric point; RT: Room temperature; TF: Transcription factor; TW: Turgid weight; WT: Wild-type; $\mu \mathrm{M}$ : micromolar

\section{Acknowledgements}

We thank Prof. Jia Li (School of Life Sciences, Lanzhou University, Lanzhou) for providing us A. tumefaciens strain GV3101 and seeds of A. thaliana respectively. This work was supported by the Major Program of Joint Funds (Sinkiang) of the National Natural Science Foundation of China (grant U1303282).

\section{Funding}

This work was supported by the Major Program of Joint Funds (Sinkiang) of the National Natural Science Foundation of China (grant U1303282).

Availability of data and materials

All related data are available within the manuscript and its additional files.

\section{Authors' contributions}

FL, ZX and ZY conceived the work and revised the manuscript. HIB designed the research, performed the experiments, and drafted the manuscript. EC, QG, GXY, GZ and XW helped design the work and analysis, revise the manuscript and contributed reagents and analysis tools. Z Y and GXY helped revised the manuscript with constructive discussions. All authors read and approved the final manuscript.

Ethics approval and consent to participate Not applicable.

Consent for publication Not applicable.

Competing interests

The authors declare that they have no competing interests.

\section{Publisher's Note}

Springer Nature remains neutral with regard to jurisdictional claims in published maps and institutional affiliations. 
Received: 31 January 2017 Accepted: 20 July 2017 Published online: 22 August 2017

\section{References}

1. Bohnert HJ, Gong QQ, Li PH, Ma SS. Unraveling abiotic stress tolerance mechanisms - getting genomics going. Curr Opin Plant Biol. 2006;9(2):180-8.

2. Du H, Zhang L, Liu L, Tang XF, Yang WJ, Wu YM, Huang YB, Tang YX. Biochemical and molecular characterization of plant MYB transcription factor family. Biochemistry-Moscow+. 2009;74(1):1-11.

3. Lippold F, Sanchez DH, Musialak M, Schlereth A, Scheible WR, Hincha DK, Udvardi MK. AtMyb41 regulates transcriptional and metabolic responses to osmotic stress in Arabidopsis. Plant Physiol. 2009;149(4):1761-72.

4. Klempnauer $\mathrm{KH}$, Gonda TJ, Bishop JM. Nucleotide sequence of the retroviral leukemia gene $\mathrm{v}$-myb and its cellular progenitor c-myb: the architecture of a transduced oncogene. Cell. 1982;31(2 Pt 1):453-63.

5. Paz-Ares J, Ghosal D, Wienand U, Peterson PA, Saedler $H$. The regulatory $\mathrm{C} 1$ locus of Zea Mays encodes a protein with homology to myb protooncogene products and with structural similarities to transcriptional activators. EMBO J. 1987;6(12):3553-8.

6. Hichri I, Barrieu F, Bogs J, Kappel C, Delrot S, Lauvergeat V. Recent advances in the transcriptional regulation of the flavonoid biosynthetic pathway. J Exp Bot. 2011;62(8):2465-83.

7. Baldoni E, Genga A, Cominelli E. Plant MYB transcription factors: their role in drought response mechanisms. Int J Mol Sci. 2015;16(7):15811-51.

8. Dubos C, Stracke R, Grotewold E, Weisshaar B, Martin C, Lepiniec L. MYB transcription factors in Arabidopsis. Trends Plant Sci. 2010;15(10):573-81.

9. He QL, Jones DC, Li W, Xie FL, Ma J, Sun RR, Wang QL, Zhu SJ, Zhang BH. Genome-wide identification of R2R3-MYB genes and expression analyses during abiotic stress in Gossypium Raimondii. Sci Rep-Uk. 2016;6

10. Williams CE, Grotewold E. Differences between plant and animal myb domains are fundamental for DNA binding activity, and chimeric Myb domains have novel DNA binding specificities. J Biol Chem. 1997;272(1):563-71.

11. Jia L, Clegg MT, Jiang T. Evolutionary dynamics of the DNA-binding domains in putative R2R3-MYB genes identified from rice subspecies indica and japonica genomes. Plant Physiol. 2004;134(2):575-85.

12. Kanei-Ishii C, Sarai A, Sawazaki T, Nakagoshi H, He DN, Ogata K, Nishimura Y, Ishii S. The tryptophan cluster: a hypothetical structure of the DNA-binding domain of the myb protooncogene product. J Biol Chem. 1990;265(32):19990-5.

13. Lipsick JS. One billion years of Myb. Oncogene. 1996;13(2):223-35.

14. Stracke R, Werber M, Weisshaar B. The R2R3-MYB gene family in Arabidopsis Thaliana. Curr Opin Plant Biol. 2001:4(5):447-56.

15. Finkelstein RR, Gampala SS, Rock CD. Abscisic acid signaling in seeds and seedlings. Plant Cell. 2002;14(Suppl):S15-45

16. Shinozaki K, Yamaguchi-Shinozaki K. Molecular responses to dehydration and low temperature: differences and cross-talk between two stress signaling pathways. Curr Opin Plant Biol. 2000;3(3):217-23.

17. Lu PL, Chen NZ, An R, Su Z, Qi BS, Ren F, Chen J, Wang XC. A novel drought-inducible gene, ATAF1, encodes a NAC family protein that negatively regulates the expression of stress-responsive genes in Arabidopsis. Plant Mol Biol. 2007;63(2):289-305.

18. Zhao BY, Hu YF, Li JJ, Yao X, Liu KD. BnaABF2, a bZIP transcription factor from rapeseed (Brassica napus L.), enhances drought and salt tolerance in transgenic Arabidopsis. Bot Stud. 2016:57.

19. Ren XZ, Chen ZZ, Liu Y, Zhang HR, Zhang M, Liu QA, Hong XH, Zhu JK, Gong ZZ. ABO3, a WRKY transcription factor, mediates plant responses to abscisic acid and drought tolerance in Arabidopsis. Plant J. 2010;63(3):417-29.

20. Qin F, Shinozaki K, Yamaguchi-Shinozaki K. Achievements and challenges in understanding plant abiotic stress responses and tolerance. Plant \& cell physiology. 2011;52(9):1569-82.

21. Chen M, Wang QY, Cheng XG, Xu ZS, Li LC, Ye XG, Xia LQ, Ma YZ. GmDREB2, a soybean DRE-binding transcription factor, conferred drought and high-salt tolerance in transgenic plants. Biochem Biophys Res Commun. 2007;353(2):299-305

22. Abe H, Urao T, Ito T, Seki M, Shinozaki K, Yamaguchi-Shinozaki K. Arabidopsis AtMYC2 (bHLH) and AtMYB2 (MYB) function as transcriptional activators in abscisic acid signaling. Plant Cell. 2003;15(1):63-78.

23. Jung C, Seo JS, Han SW, Koo YJ, Kim CH, Song SI, Nahm BH, Choi YD, Cheong JJ. Overexpression of AtMYB44 enhances stomatal closure to confer abiotic stress tolerance in transgenic Arabidopsis. Plant Physiol. 2008;146(2):623-35.
24. Chen YH, Zhang XB, Wu W, Chen ZL, Gu HY, Qu LJ. Overexpression of the wounding-responsive gene AtMYB15 activates the shikimate pathway in Arabidopsis. J Integr Plant Biol. 2006;48(9):1084-95.

25. Chen TZ, Li WJ, Hu XH, Guo JR, Liu AM, Zhang BL. A cotton MYB transcription factor, GbMYB5, is positively involved in plant adaptive response to drought stress. Plant Cell Physiol. 2015;56(5):917-29.

26. Denekamp M, Smeekens SC. Integration of wounding and osmotic stress signals determines the expression of the AtMYB102 transcription factor gene. Plant Physiol. 2003;132(3):1415-23.

27. Wang RK, Cao ZH, Hao YJ. Overexpression of a R2R3 MYB gene MdSIMYB1 increases tolerance to multiple stresses in transgenic tobacco and apples. Physiol Plant. 2014;150(1):76-87.

28. Yang A, Dai XY, Zhang WH. A R2R3-type MYB gene, OsMYB2, is involved in salt, cold, and dehydration tolerance in rice. J Exp Bot. 2012;63(7):2541-56.

29. Su LT, Li JW, Liu DQ, Zhai Y, Zhang HJ, Li XW, Zhang QL, Wang Y, Wang QY. A novel MYB transcription factor, GmMYBJ1, from soybean confers drought and cold tolerance in Arabidopsis Thaliana. Gene. 2014:538(1):46-55.

30. Su LT, Wang Y, Liu DQ, Li XW, Zhai Y, Sun X, Li XY, Liu YJ, Li JW, Wang QY The soybean gene, GmMYBJ2, encodes a R2R3-type transcription factor involved in drought stress tolerance in Arabidopsis thaliana. Acta Physiol Plant. 2015:37(7).

31. Liao Y, Zou HF, Wang HW, Zhang WK, Ma B, Zhang JS, Chen SY. Soybean GmMYB76, GmMYB92, and GmMYB177 genes confer stress tolerance in transgenic Arabidopsis plants. Cell Res. 2008;18(10):1047-60.

32. Yuan Y, Qi LJ, Yang J, Wu C, Liu YJ, Huang LQ: A Scutellaria Baicalensis R2R3-MYB gene, SbMYB8, regulates flavonoid biosynthesis and improves drought stress tolerance in transgenic tobacco (vol 120, pg 961, 2015). Plant Cell Tiss Org 2015, 120(3):973-973.

33. Brown DC. Cotton: origin, history, technology, and production. Agr Hist. 2000;74(4):823-4.

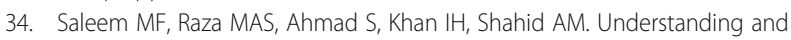
mitigating the impacts of drought stress in cotton- a review. Pak J Agr Sci. 2016;53(3):609-23.

35. Li FG, Fan GY, Wang KB, Sun FM, Yuan YL, Song GL, Li Q, Ma ZY, Lu CR, Zou CS, et al. Genome sequence of the cultivated cotton Gossypium Arboreum. Nat Genet. 2014;46(6):567-72.

36. Zhang XY, Yao DX, Wang QH, Xu WY, Wei Q, Wang CC, Liu CL, Zhang CJ,

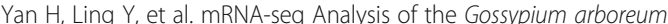
transcriptome Reveals Tissue Selective Signaling in Response to Water Stress during Seedling Stage. PLoS One. 2013:8(1).

37. Zhong $R Q$, Lee $\mathrm{CH}$, Zhou JL, McCarthy RL, Ye ZH. A battery of transcription factors involved in the regulation of secondary Cell Wall biosynthesis in Arabidopsis. Plant Cell. 2008;20(10):2763-82.

38. Hetherington AM, Woodward Fl. The role of stomata in sensing and driving environmental change. Nature. 2003:424(6951):901-8.

39. Malamy JE. Intrinsic and environmental response pathways that regulate root system architecture. Plant Cell and Environment. 2005;28(1):67-77.

40. Cheng LQ, Li XX, Huang X, Ma T, Liang Y, Ma XY, Peng XJ, Jia JT, Chen SY, Chen $Y$, et al. Overexpression of sheepgrass R1-MYB transcription factor LCMYB1 confers salt tolerance in transgenic Arabidopsis. Plant Physiol Bioch. 2013:70:252-60.

41. Ma T, Li ML, Zhao AG, Xu X, Liu GS, Cheng LQ. LCWRKY5: an unknown function gene from sheepgrass improves drought tolerance in transgenic Arabidopsis. Plant Cell Rep. 2014;33(9):1507-18.

42. Sabbagh E, Lakzayi M, Keshtehgar A, Rigi K: The effect of salt stress on respiration, PSII function, chlorophyll, carbohydrate and nitrogen content in crop plants. 2014

43. Muhammad J, DEOG BL, KWANG YJ, Muhammad A, SHEONG CL, EUI SR EFFECT OF SALT (NACL) STRESS ON GERMINATION AND EARLY SEEDLING GROWTH OF FOUR VEGETABLES SPECIES. J Cent Eur Agric. 2006;6(2):273-82.

44. Zhu JK. Regulation of ion homeostasis under salt stress. Curr Opin Plant Biol. 2003:6(5):441-5.

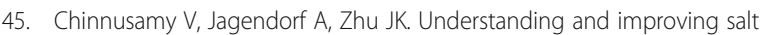
tolerance in plants. Crop Sci. 2005:45(2):437-48.

46. de Oliveira AB, Mendes Alencar NL, Gomes-Filho E: Comparison between the water and salt stress effects on plant growth and development. 2013.

47. Munns R, Tester M. Mechanisms of salinity tolerance. Annu Rev Plant Biol. 2008:59:651-81.

48. Jakab G, Ton J, Flors V, Zimmerli L, Metraux JP, Mauch-Mani B. Enhancing Arabidopsis salt and drought stress tolerance by chemical priming for its abscisic acid responses. Plant Physiol. 2005;139(1):267-74. 
49. JAMIL M, DEOG BAE L, KWANG YONG J, ASHRAF M, SHEONG CHUN L, EUI SHIK R. Effect of salt ( $\mathrm{NaCl}$ ) stress on germination and early seedling growth of four vegetables species. J Cent Eur Agric. 2006;7(2):273-82.

50. Sun X, Li Y, Cai H, Bai X, Ji W, Ding X, Zhu Y. The Arabidopsis AtbZIP1 transcription factor is a positive regulator of plant tolerance to salt, osmotic and drought stresses. J Plant Res. 2012;125(3):429-38.

51. Min $\mathrm{H}$, Zheng J, Wang J. Maize ZmRAV1 contributes to salt and osmotic stress tolerance in transgenic arabidopsis. J Plant Biol. 2014;57(1):28-42.

52. Zhang LN, Zhang LC, Xia C, Zhao GY, Jia JZ, Kong XY. The novel wheat transcription factor TaNAC47 enhances multiple abiotic stress tolerances in transgenic plants. Front Plant Sci. 2016;6

53. Yue YS, Zhang MC, Zhang JC, Tian XL, Duan LS, Li ZH. Overexpression of the AtLOS5 gene increased abscisic acid level and drought tolerance in transgenic cotton. J Exp Bot. 2012;63(10):3741-8.

54. Hu HH, Dai MQ, Yao JL, Xiao BZ, Li XH, Zhang QF, Xiong LZ. Overexpressing a NAM, ATAF, and CUC (NAC) transcription factor enhances drought resistance and salt tolerance in rice. P Natl Acad Sci USA. 2006;103(35):12987-92.

55. $\mathrm{Ko} \mathrm{JH}$, Yang SH, Han KH. Upregulation of an Arabidopsis RING-H2 gene, XERICO, confers drought tolerance through increased abscisic acid biosynthesis. Plant J. 2006;47(3):343-55.

56. Zhang LC, Liu GX, Zhao GY, Xia C, Jia JZ, Liu X, Kong XY. Characterization of a wheat R2R3-MYB transcription factor gene, TaMYB19, involved in enhanced abiotic stresses in Arabidopsis. Plant Cell Physiol. 2014;55(10):1802-12.

57. Cominelli E, Galbiati M, Vavasseur A, Conti L, Sala T, Vuylsteke M, Leonhardt N, Dellaporta SL, Tonelli C. A guard-cell-specific MYB transcription factor regulates stomatal movements and plant drought tolerance. Curr Biol. 2005;15(13):1196-200.

58. Lu PT, Kang M, Jiang XQ, Dai FW, Gao JP, Zhang CQ. RhEXPA4, a rose expansin gene, modulates leaf growth and confers drought and salt tolerance to Arabidopsis. Planta. 2013;237(6):1547-59.

59. Xiong HY, Li JJ, Liu PL, Duan JZ, Zhao Y, Guo X, Li Y, Zhang HL, Ali J, Li ZC. Overexpression of OsMYB48-1, a Novel MYB-Related Transcription Factor, Enhances Drought and Salinity Tolerance in Rice. PLoS One. 2014:9(3).

60. Li GJ, Nasar V, Yang YX, Li W, Liu B, Sun LJ, Li DY, Song FM. Arabidopsis poly(ADP-ribose) glycohydrolase 1 is required for drought, osmotic and oxidative stress responses. Plant Sci. 2011;180(2):283-91.

61. Ashraf M, Foolad MR. Roles of glycine betaine and proline in improving plant abiotic stress resistance. Environ Exp Bot. 2007:59(2):206-16.

62. Yu H, Chen X, Hong YY, Wang Y, Xu P, Ke SD, Liu HY, Zhu JK, Oliver DJ, Xiang CB. Activated expression of an Arabidopsis HD-START protein confers drought tolerance with improved root system and reduced stomatal density. Plant Cell. 2008;20(4):1134-51.

63. Ding ZH, Li SM, An XL, Liu XJ, Qin HM, Wang D. Transgenic expression of MYB15 confers enhanced sensitivity to abscisic acid and improved drought tolerance in Arabidopsis Thaliana. J Genet Genomics. 2009;36(1):17-29.

64. Lopez-Molina L, Mongrand S, Chua NH. A postgermination developmental arrest checkpoint is mediated by abscisic acid and requires the AB15 transcription factor in Arabidopsis. P Natl Acad Sci USA. 2001;98(8):4782-7.

65. Mittal A, Gampala SSL, Ritchie GL, Payton P, Burke JJ, Rock CD. Related to ABA-Insensitive3(AB|3)/Viviparous1 and AtABI5 transcription factor coexpression in cotton enhances drought stress adaptation. Plant Biotechnol J. 2014;12(5):578-89.

66. Narusaka Y, Nakashima K, Shinwari ZK, Sakuma Y, Furihata T, Abe H, Narusaka M, Shinozaki K, Yamaguchi-Shinozaki K. Interaction between two cis-acting elements, ABRE and DRE, in ABA-dependent expression of Arabidopsis rd29A gene in response to dehydration and high-salinity stresses. Plant J. 2003;34(2):137-48.

67. Seo PJ, Xiang FN, Qiao M, Park JY, Lee YN, Kim SG, Lee YH, Park WJ, Park CM. The MYB96 transcription factor mediates abscisic acid signaling during drought stress response in Arabidopsis. Plant Physiol. 2009;151(1):275-89.

68. Clough SJ, Bent AF. Floral dip: a simplified method for agrobacteriummediated transformation of Arabidopsis Thaliana. Plant J. 1998;16(6):735-43.

69. Qin YX, Wang MC, Tian YC, He WX, Han L, Xia GM. Over-expression of TaMYB33 encoding a novel wheat MYB transcription factor increases salt and drought tolerance in Arabidopsis. Mol Biol Rep. 2012;39(6):7183-92.

70. Dhanda SS, Sethi GS. Inheritance of excised-leaf water loss and relative water content in bread wheat (Triticum Aestivum). Euphytica. 1998;104(1):39-47.
71. Parida AK, Dagaonkar VS, Phalak MS, Umalkar GV, Aurangabadkar LP. Alterations in photosynthetic pigments, protein and osmotic components in cotton genotypes subjected to short-term drought stress followed by recovery. Plant Biotechnol Rep. 2007;1(1):37-48.

72. Zhao FL, Ma JH, Li LB, Fan SL, Guo YN, Song MZ, Wei HL, Pang CY, Yu SX. GhNAC12, a neutral candidate gene, leads to early aging in cotton (Gossypium Hirsutum L). Gene. 2016;576(1):268-74.

73. Pei ZM, Kuchitsu K, Ward JM, Schwarz M, Schroeder JI. Differential abscisic acid regulation of guard cell slow anion channels in Arabidopsis wild-type and abi1 and abi2 mutants. Plant Cell. 1997;9(3):409-23.

74. Schneider CA, Rasband WS, Eliceiri KW. NIH image to ImageJ: 25 years of image analysis. Nat Methods. 2012;9(7):671-5.

75. Livak KJ, Schmittgen TD. Analysis of relative gene expression data using real-time quantitative PCR and the $2(T)(-$ Delta Delta $C)$ method. Methods. 2001;25(4):402-8.

\section{Submit your next manuscript to BioMed Central and we will help you at every step:}

- We accept pre-submission inquiries

- Our selector tool helps you to find the most relevant journal

- We provide round the clock customer support

- Convenient online submission

- Thorough peer review

- Inclusion in PubMed and all major indexing services

- Maximum visibility for your research

Submit your manuscript at www.biomedcentral.com/submit
C Biomed Central 